\title{
Vertebral Artery Injury Associated with a Jefferson Fracture
}

\author{
Gregory S. Walsh and Michael D. Cusimano
}

\begin{abstract}
Background: The evaluation and treatment of Jefferson fractures, a burst fracture of the ring of $\mathrm{Cl}$, has been well documented in the medical literature. Vertebral artery injury associated with a Jefferson fracture is very rare. Methods: The case study technique was used to summarize the case. Review of the literature was performed to discuss the case. Retrospective chart review of the 174 patients with cervical fractures admitted to St. Michael's Hospital from 1989-1994 was also performed. Results: The case of a patient with a Jefferson fracture, with bilateral lateral displacement of the lateral masses causing bilateral vertebral artery occlusions resulting in a lateral medullary and cerebellar infarction is reported. A review of the literature is provided. Conclusion: A high index of suspicion for this injury is paramount, especially in patients with multiple trauma, where the diagnosis of Jefferson fractures can be delayed.
\end{abstract}

RÉSUMÉ: Lésion de l'artère vertébrale associée à une fracture de Jefferson. Introduction: L'évaluation et le traitement des fractures de Jefferson, une fracture par éclatement de l'anneau de $\mathrm{Cl}$, sont bien documentés dans la littérature médicale. Il est très rare qu'une lésion de l'artère vertébrale soit associée à une fracture de Jefferson. Méthodes: Nous présentons une étude de cas ainsi qu'une revue de la littérature pour en discuter. Nous avons également révisé les dossiers de 174 patients ayant subi des fractures cervicales qui ont été admis à l'Hôpital St-Michael entre 1989 et 1994. Résultats: Nous rapportons le cas d'un patient avec fracture de Jefferson et déplacement latéral bilatéral des masses latérales causant un infarcissement médullaire et cérébelleux suite à une occlusion bilatérale des artères vertébrales. Nous présentons également une revue de la littérature. Conclusions: Il est très important de considérer cette éventualité, surtout chez les polytraumatisés chez qui le diagnostic de fracture de Jefferson peut être tardif.

Can. J. Neurol. Sci. 1995; 22: 308-311

A Jefferson fracture usually results from the axial compression of the occiput directly downward on the arch of the first cervical vertebra, causing the ring of $\mathrm{Cl}$ to fail in tension. ${ }^{1-3}$ The fractures usually occur bilaterally just anterior and just posterior to the atlanto-occipital articulating facet, resulting in an anterior and posterior arch, and two lateral masses. ${ }^{2}$ Because of the nature of the angulation of the articulation between the first and second cervical vertebrae, the downward force will result in a relatively symmetrical spreading of the lateral masses. ${ }^{2}$ Since the fracture fragments tend to spread outwards, neurological deficit secondary to a Jefferson fracture is rare, but has been reported especially if a concomitant fracture of the odontoid exists. ${ }^{1,2}$ The pathognomonic plain radiograph for the diagnosis of a Jefferson fracture remains the open-mouth anteroposterior radiograph of the articulating facets of the first and second cervical vertebrae. ${ }^{1-3}$

In the English literature, only one report of vertebral artery injury associated with a Jefferson fracture has been identified. ${ }^{4}$ In this report, Siegel and Alberts describe an unusual type of Jefferson fracture with post-mortem studies demonstrating occlusion of the vertebral artery. The publication, however, did not focus on the clinical significance of this injury. Our case represents the first reported case of vertebral artery injury asso- ciated with a Jefferson fracture that was recognized pre-mortem and successfully managed.

\section{CaSe Report}

A 21 -year-old male was involved in a motor vehicle accident in which he was thrown 100 feet from the car. He was initially hypotensive and unresponsive and found to have a hemopneumothorax. A chest tube was inserted at a peripheral hospital. With intubation he became more responsive in his Glasgow Coma Scale which improved to 13 . He required transfusion of several units of blood and eventually underwent a laparotomy. Laparotomy demonstrated a lacerated spleen and a splenectomy was done. He failed extubation and was somewhat drowsy on the following day. A CT scan of the head was done and was essentially normal. Attempts were made to once again extubate him and once again failed. At that time he was noted to be obeying commands, responding appropriately and moving all limbs symmetrically. However, the next day it was noted that the patient's right pupil was dilated, and that he had significant left-sided hemiparesis and anisocoria. He was then transferred to our centre for further care and management.

From the Division of Neurosurgery, St. Michael's Hospital, University of Toronto, Toronto

RECEIVED JANUARY 11, 1995. ACCEPTED IN FINAL FORM MAY 2, 1995.

Reprint requests to: Dr. Michael D. Cusimano, Division of Neurosurgery, 38 Shuter Street, Toronto, Ontario, Canada M5B 1 A6 
A CT scan without contrast reviewed from the referring hospital showed that the sulci were somewhat effaced and the ventricles somewhat small. There was some question of whether the midbrain itself was hypodense. Repeat CT scans showed acute hydrocephalus and a hypodensity in the left cerebellum. His cervical spine $x$-rays showed a widened distance of $5 \mathrm{~mm}$ from the atlas to the odontoid peg. A cerebral angiogram showed bilateral vertebral artery occlusions (Figure $1 \mathrm{~A}$, B). The right vertebral artery was reconstituted through the occipital artery. MRI confirmed a left inferior cerebellar infarction (Figure IC, D). A CT scan of the upper cervical spine confirmed a Jefferson fracture with the lateral elements of $\mathrm{Cl}$ sustaining fractures with lateral displacement and secondly, an avulsion of the transverse atlantal ligament (Figure 2A, B). Following a ventriculostomy, his level of consciousness improved dramatically. He was anticoagulated and treated in a halo orthosis.

His later course was complicated by a pleural empyema. After recovery from his acute illness, his residual neurological deficits included vocal cord paresis, marked discoordination of the pharyngeal muscles, and a difficulty with peristalsis and tongue movement. This is consistent with a lateral medullary and cerebellar infarct likely along the vascular territory of the posterior inferior cerebellar antery. He improved markedly during rehabilitation and is now ambulating independently in a vocational course at a community college at 2 years follow up. His fractures and the avulsion of his transverse atlantal ligament healed in the halo and he was anticoagulated for a total of six months.

\section{Discussion}

Anatomically, the vertebral arteries arise from the subclavian arteries and ascend through the transverse foramina of the first six cervical vertebrae. As it exits the axial transverse foramen, the vertebral artery turns laterally to pass through the transverse foramen of the atlas, where it subsequently curves posteriorly and medially over the posterior arch of the atlas and around the atlanto-occipital joint. ${ }^{5.6}$ The vertebral artery's intimate relationship with the osseous rings of the transverse foramen put it in a precarious position, especially at the level of $\mathrm{Cl}-\mathrm{C} 2$ due to its tortuous course. Occlusion of the vertebral artery can occur even in the physiologic range of motion as has been described by Hanakita et al. ${ }^{7}$ With rotation of the head, the vertebral artery contralateral to the direction of rotation can be constricted at the level of the atlantoaxial joint and may result in vertebro-basilar

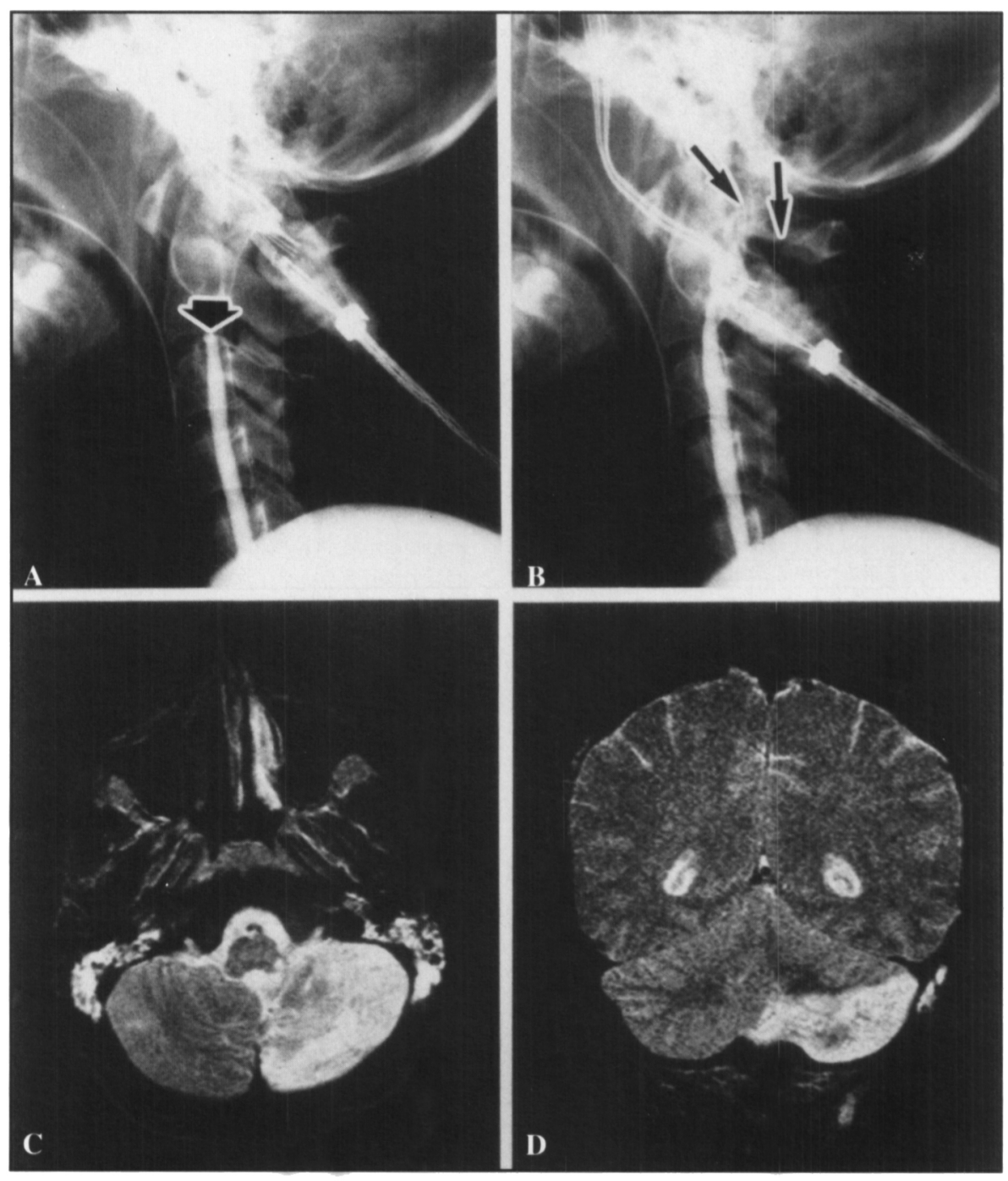

Figure 1: A) and B) (top] Cerebral arteriogram demonstrating bilateral vertebral artery occlusions, (large arrow in A) and left sided arrow in B)] and fracture of the posterior elements of $C I$ in $B$ ). C) and D) [bottom] Axial and coronal T2 weighted MRI images demonstrating the PICA territory infarction associated with this patient's injury. 

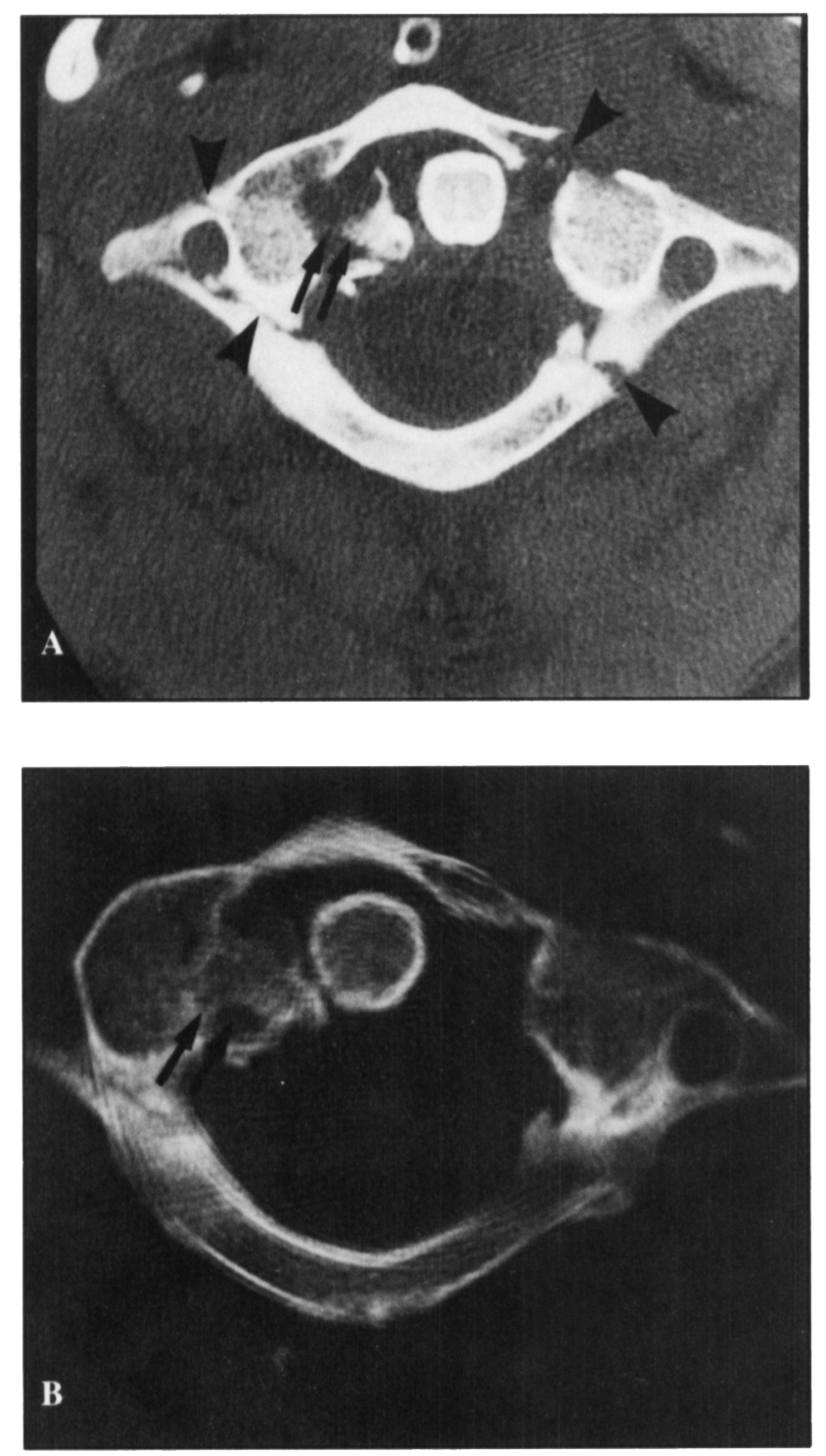

Figure 2: A) CT scan demonstrating a Jefferson fracture (arrow heads demonstrate fracture lines) with lateral displacement of the foramen transversaria which encase the vertebral arteries. Avulsion of the transverse atlantal ligament (arrows) can also be seen. B) CT scan of $C I$ six months after injury demonstrating healing of the fractures and avulsed ligament (arrows).

symptomology. ${ }^{7}$ In the upper cervical region, a relatively small external force, such as that supplied by a translating fracture fragment, should be sufficient to cause injury to the vertebral artery.

The mechanism of injury proposed for such blunt trauma invariably consists of a stretching, tearing, or constriction of the vessel $^{8.9}$ Such a force could cause a disruption of the intimal layer of the vessel wall leading to an aggregation of platelets on the exposed subintimal connective tissue, acute or complete thrombotic occlusion, subintimal haematoma, dissection of the vessel wall, pseudoaneurysm formation, or possible distal embolization. ${ }^{3,8 \cdot 10}$

Symptoms such as altered consciousness, nystagmus, swallowing difficulties, limb and trunk ataxia, dysarthria, and diplop- ia may be indicative of a vertebral artery injury. ${ }^{8.10}$ Unilateral occlusion of the vertebral artery may be clinically insignificant if the patency of the contralateral artery is not compromised and blood flow to the PICA is preserved." Asymptomatic injury from acute bilateral occlusion of the vertebral arteries is extremely rare and can only occur due to the presence of the intracranial anastomotic channels provided by the Circle of Willis. ${ }^{11.12}$ An ascending thrombosis of the vertebral artery will occlude the PICA and may result in a lateral medullary or cerebellar infarction, as demonstrated by our patient. ${ }^{3,11,13}$

Injury to the vertebral artery in the upper cervical spine region has been reported in cases such as chiropractic manipulation, atlanto-occipital dislocation, atlantoaxial dislocation secondary to rheumatoid arthritis, and transverse process fractures of the atlas. ${ }^{7 \cdot 10,14-17}$ Fracture dislocations of the cervical vertebrae can pose a serious threat to the patency of the vertebral arteries and can have devastating neurological sequelae. ${ }^{8-15,18-20}$ Our case represents the only clinically recognized vertebral artery injury occurring in 174 patients treated for cervical spine trauma at St. Michael's Hospital during a five year period. Recent reports indicate that the incidence of this particular type of injury may be more common than previously believed. Louw et al. ${ }^{19}$ reported that $75 \%$ of his 12 patients with facet joint dislocations had also injured their vertebral artery, as demonstrated by intra-arterial digital subtraction angiography. Twenty-six patients suffering trauma to the midcervical spine (C2-C6) studied by Willis et al., ${ }^{20}$ underwent preoperative vertebral angiography to find that $46 \%$ (12 patients) had been diagnosed with vertebral artery injury. In Louw et al.'s study, 2 of the 9 patients with vertebral artery occlusions had transient neurological deficits, which resolved spontaneously within two months, while none of Willis et al.'s patients evidenced any neurological dysfunction.

The bilateral lateral displacement in our patient's Jefferson fracture had an average lateral displacement of $9 \mathrm{~mm}$ and was sufficient to bilaterally occlude his vertebral arteries and result in ischemic injury along the territory of the PICA. Parent et al. ${ }^{12}$ described 5 patients with lateral dislocation of the lower cervical spine (C5-C7) who suffered injury to their vertebral arteries. In contrast to Louw et al.'s and Willis et al.'s studies, all five patients were symptomatic with respect to their vertebral artery injury with two cases presenting with medullary and cerebellar infarction resulting in the patient's death.

Most reports indicate a latency period between the time of initial trauma and the presentation of vertebro-basilar symptomology. ${ }^{89,12,13}$ The tendency for delayed ischemia is explained by the time interval necessary for establishment of a complete thrombosis or distal embolization to take place. In addition, the diagnosis of a Jefferson fracture in the polytraumatized patient can also be delayed due to a number of factors including a lack of neurological signs, treatment of more apparent and immediately life threatening injuries, and the failure to give a thorough radiological evaluation of the upper cervical spine in patients who have had an associated head injury. ${ }^{1.2}$ This highlights the need for a critical examination of the upper cervical spine in polytraumatized patients.

The treatment for arteries with intimal disruptions usually consists of some form of antiplatelet or anticoagulation therapy. ${ }^{12.20}$ Surgical ligation or endovascular balloon occlusion have been 
suggested as alternative therapies for patients with severe vertebral artery injury or symptoms of vertebrobasilar embolism. ${ }^{21.22}$ Our patient's Jefferson fracture was treated conservatively with a halo vest, since the avulsion of the transverse atlantal ligament included a bony fragment, and the management of his vertebral arteries included anticoagulation for a total of six months.

Our case demonstrates that a Jefferson fracture, which usually results in the symmetrical lateral displacement of the lateral masses, can pose a serious threat to the patency of both vertebral arteries. Since the diagnosis of Jefferson fractures may be delayed in the polytraumatized patient, the astute clinician must maintain a high index of suspicion for the injury we have described.

\section{REFERENCES}

1. Kesterson L, Benzel E, Orrison W, Coleman J. Evaluation and treatment of atlas burst fractures (Jefferson fractures). J Neurosurg 1991; 75: 213-220.

2. Levine AM, Edwards CC. Fractures of the atlas. J Bone Joint Surg[Am] 1991; 73: 680-691.

3. Pierce DS, Barr JS, Fractures and Dislocations at the Base of the Skull and Upper Cervical Spine. In: Sherk HH, Dunn EJ, Eismont FJ, et al, eds. The Cervical Spine, 2nd Editon. Philadelphia: J.B. Lippincott Co., 1989: 312-324.

4. Siegel M, Alberts R. Unusual sign of a Jefferson fracture. Spine 1992; 17: 605-606.

5. Stephens RB, Stilwell DL. Arteries and Veins of the Human Brain. Springfield, Illinois: Charles C. Thomas, 1969; 71-123.

6. Williams PL, Warwick R, Dyson M, Bannister LH. Gray's Anatomy, 37th Edition. New York: Churchill Livingstone, 1989; 315-319, 750-755.

7. Hanakita J, Hidenori M, Nagayasu S, et al. Angiographic examination and surgical treatment of bow hunter's stroke. Neurosurgery 1988; $23: 228-232$
8. Cornacchia LG, Abitol JJ, Heller J, et al. Blunt injuries to the extracranial cerebral vessels associated with spine fractures. Spine 1991; 16: S506-S510.

9. Deen, Jr. HG, McGirr SJ. Vertebral artery injury associated with cervical spine fracture. Spine 1992; 17: 230-234.

10. Lyness SS, Simeone FA. Vascular complications of upper cervical spine injuries. Orthop Clin North Am 1978; 9: 1029-1038.

11. Schwarz N, Buchinger W, Guadernak T, et al. Injuries to the cervical spine causing vertebral artery trauma: case reports. J Trauma 1991; 31: 127-133.

12. Parent AD, Harkey HL, Touchstone DA, et al. Lateral cervical spine dislocation and vertebral artery injury. Neurosurgery 1992: 31: $501-509$.

13. Jabre A. Subintimal dissection of the vertebral artery in subluxation of the cervical spine. Neurosurgery 1991; 29: 912-915.

14. Lee C, Woodring JH, Walsh JW. Carotid and vertebral artery injury in survivors of atlanto-occipital dislocation: case reports and literature review. J Trauma 1991; 31: 401-407.

15. Woodring JH, Lee C, Duncan V. Transverse process fractures of the cervical vertebrae: are they significant? J Trauma 1993; 34: 797-802.

16. Contostavlos DM. Massive subarachnoid hemorrhage due to laceration of the vertebral artery associated with fracture of the transverse process of the atlas. J Forensic Sci 1971; 16: 40-56.

17. Raskind $\mathrm{R}$, North $\mathrm{CM}$. Vertebral artery injuries following chiropractic cervical spine manipulation - case reports. Angiology 1990; 41: 445-452.

18. Lee C, Woodring JH. Sagitally oriented fractures of the lateral masses of the cervical vertebrae. J Trauma 1991; 31: 1638-1643.

19. Louw JA, Mafoyane NA, Small B, Neser CP. Occlusion of the vertebral artery in cervical spine dislocations. J Bone Joint Surg[Br] 1990; 72: 679-681.

20. Willis BK, Greiner F, Orrison WW, Benzel EC. The incidence of vertebral artery injury after midcervical spine fracture of subluxation. Neurosurgery $1994 ; 34: 435-442$.

21. Aymard A, Gobin YP, Hodes JE, et al. Endovascular occlusion of vertebral arteries in the treatment of unclippable vertebrobasilar aneurysms. J Neurosurg 1991; 74: 393-398.

22. Meier DE, Brink BE, Fry WJ. Vertebral artery trauma: acute recognition and treatment. Arch Surg 1981; 1 16: 236-239. 